\title{
(DES)CALÇADAS URBANAS, A FALTA DE IDENTIDADE NO CHÃO PROJETADO. Um olhar pelo bairro da Pelinca em Campos dos Goytacazes/RJ.
}

\author{
Lídia Maria Tavares Martins \\ Doutora FAUL - Faculdade de Arquitetura da Universidade de Lisboa e Colaboradora do CIAUD; Professora \\ do Curso de Arquitetura e Urbanismo do ISECENSA -Campos dos Goytacazes - RJ, Brasil. \\ lidiamtmartins@gmail.com
}

\section{Francisco Carlos Almeida do Nascimento e Oliveira}

Membro Efetivo do Centro de Investigação em Arquitetura-CIAUD; Professor naFaculdade de Arquitetura da Universidade de Lisboa da Universidade de Lisboa, Portugal.

fcoliveira@fa.ulisboa.pt

\section{RESUMO}

O artigobusca encontrar um caminho, que possa resgatar e potencializar a imagem urbana da cidade, através das suas áreas públicas, mais especificamente suas calçadas, chão projetado, reforçando a importância do nome "Chão", enquanto afirmação de lugar.Analisar as possibilidades de requalificação desses espaços de convívio, em especial no bairro da Pelinca na cidade de Campos dos Goytacazes (RJ),aumentando o debate sobre a urgente necessidade de se promover uma cidade mais humana, inclusiva, sustentável e resiliente, produzindo e transformando rapidamente o espaço urbano construído, as calçadas, aqui denominadas (Des)Calçadas, abordando nessa denominação, com o uso do prefixo Des, a negação do espaço público e a desconexão existente com as pessoas, em um local acessível, agradável e com valorização de lugar, combinando infraestrutura com os princípios de acessibilidade e mobilidade, e incorporando conceitos de identidade urbana, capaz de desenvolver o sentimento de pertencimento das pessoas e seus lugares.

Palavras-chave:Identidade urbana, acessibilidade e mobilidade, requalificação.

Linha de Investigação: 1. Cidade e projeto Tópico: Projeto urbano e espaço público.

\section{ABSTRACT}

The article seeks to find a way, which can rescue and enhance the urban image of the city, through its public areas, more specifically its sidewalks, projected floor, reinforcing the importance of the name "Chão", as an affirmation of place. Analyze the possibilities of requalifying these living spaces, especially in the Pelinca 


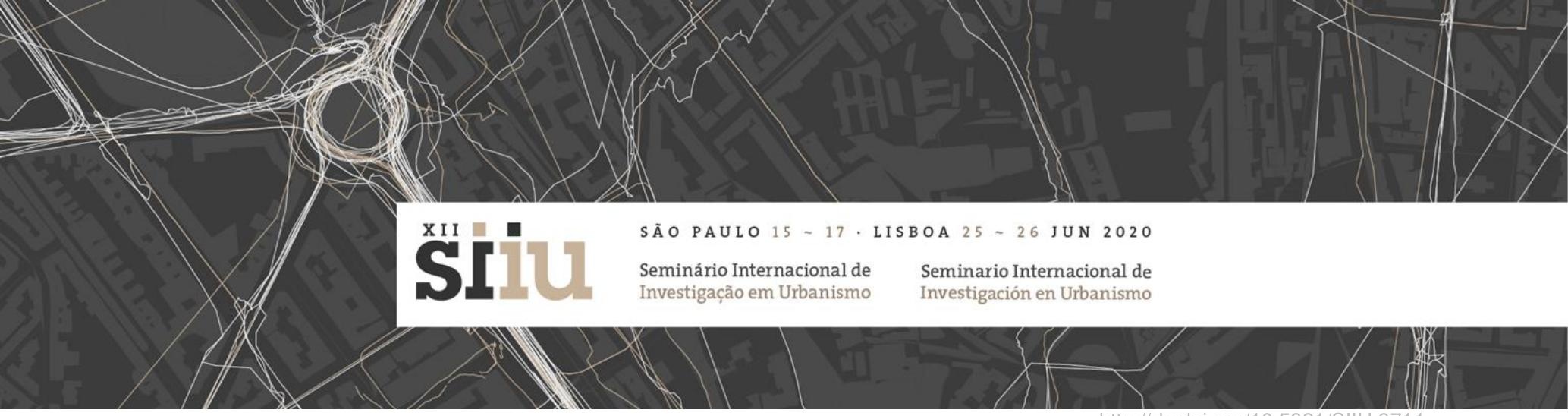

http://dx.doi.org/10.5821/SIIU.9711

neighborhood in the city of Campos dos Goytacazes (RJ), increasing the debate on the urgent need to promote a more humane, inclusive, sustainable and resilient city, quickly producing and transforming the built urban space, the sidewalks, here called (Des) Sidewalks, addressing this denomination, using the prefix Des, the denial of public space and the disconnection existing with people, in an accessible, pleasant and placeworthy place, combining infrastructure with the principles of accessibility and mobility, and incorporating concepts of urban identity, capable of developing the feeling of belonging of people people and their places.

Keywords:Urban identity, accessibility and mobility, requalification.

Thematic clusters: 1. City and Project Topic: Urban project and public space 


\title{
XII
}

Seminário Internacional de Investigação em Urbanismo

\section{Introdução}

No planejamento e na construção das cidades é importante se levar em conta vários elementos: cultura, etnias, ambiente natural etc. A cidade fala com seus habitantes e essa linguagem, "a linguagem da cidade", como ela se comunica e se conecta com as pessoas, pode ser percebida através das imagens que construímos e organizamos no nosso cotidiano, podendo ser decompostas em três componentes: identidade, estrutura e significado (Lynch, 2006). O livro Cidade de Desejo entre Desenhos de Cidades, destaca:

\begin{abstract}
"A cidade é por excelência, o lugar onde o homem pode encontrar a sua mais expressiva dimensão. É o lugar de exponenciais fontes de informações, múltiplas formas de comunicação, absoluta mobilidade, diversidade de culturas e formações, oportunidade de ofertas, infinitas possibilidades de relações sociais. Lugar de encontros, culturas, religiões, mas também memórias, ideias, atitudes, aprendizagens. Em síntese, a cidade que é a polis é o lugar, de excelência, da própria democracia."(TELES, 2013, p. 17) (grifo nosso).
\end{abstract}

É no meio dos desejos e dos desenhos de cidades, nos traçados das ruas e nas malhas urbanas que encontramos as calçadas, importante área pública do sistema de trânsito, junto com as vias de circulação de veículos. Importante observar, que a implantação e construção das calçadas não está, de forma alguma, desconectadas das ruas, dos bairros e das cidades. Espaço público construído, chão projetado exclusivamente para o trânsito seguro de todos os pedestres, reforçando aqui, a importância do nome "Chão", enquanto ideia de pertencimento, identidade urbana e afirmação de lugar.

As ruas, mais diretamente suas calçadas têm um papel preponderante na questão do planejamento e construção dos espaços públicos atendendo as muitas finalidades e cumprindo assim suas funções sociais. Espaço de vivência, includente e democrático deveria, obviamente, estar bastante conectado com as pessoas, seu lugar e suas memórias.

A expressão lugares de memória, citada pelo historiador francês Pierre Nora, representa muito bem o que estamos buscando demonstrar nesse artigo.

\footnotetext{
..."os lugares de memória são: lugares materiais onde a memória social se ancora e pode ser apreendida pelos sentidos; são lugares funcionais porque tem ou adquiriram a função de alicerçar memórias coletivas e são lugares simbólicos onde essa memória coletiva - vale dizer, essa identidade - se expressa e se revela. São, portanto, lugares carregados de uma vontade de memória". (NORA, 1984).
}

Assim, torna-se urgente e necessário promover cidades mais humanas, inclusivas, sustentáveis e resilientes, produzindo e transformando rapidamente o espaço urbano construído, especialmente as (Des)Calçadas, abordando nessa definição a desconexão com as pessoas, as desconformidades dos pavimentos, o desconforto de caminhar e a desqualificação das áreas públicas, em um espaço acessível, agradável e com valorização de lugar. 


\title{
XII SÃOPAULO15 $17 \cdot$ LISBOA $25 \sim 26$ JUN 2020
}

A calçada já foi o lugar perfeito para saber das novidades, encontrar amigos, brincar com crianças, desfrutar o fim da tarde ou, simplesmente, observar o tempo passar. Hábitos que hoje estão fora da realidade dos grandes e médios centros urbanos brasileiros, talvez até das cidades menores. Diante da correria, da falta de tempo, da violência, do número de veículos em circulação, e do descaso do poder público, caminhar pelas calçadas hoje deixou de ser confortável, tranquilo, saudável e principalmente seguro (Speck, 2016; Gehl, 2015).

Pedestres, ambulantes, bicicletas, mobiliário urbano aleatoriamente colocado, disputam as calçadas tornando a vida nesse espaço algo desestimulante e desinteressante.

\begin{abstract}
"A noção do passeio (sidewalk) como estrutura pedonal imprescindível, assume-se numa relação global com o espaço da cidade, como determinante para a formação da sua imagem. As estruturas pedonais assumem, deste modo, um papel primordial na formação do ideal cívico das cidades." (OLIVEIRA, 2008).
\end{abstract}

\section{Objetivo}

O objetivo maior desse artigoé apresentar um estudo parcial,abordando a falta de identidade urbana e a conexão (ou não) das (Des)Calçadas, enquanto chão projetado, no bairro da Pelinca na cidade de Campos dos Goytacazes/RJ - Brasil, com os usuários do lugar. Objetiva, ainda, avaliar o quanto a falta de identidade e a desconexão, impacta direta e/ou indiretamente, em uma maior ou menor mobilidade urbana das pessoas. A relevância deste estudo vai ao encontro de uma tendência mundial em requalificar os espaços públicos, proporcionando uma mudança na forma de se pensar a cidade, dentro de uma ótica com mais percepção acerca da valorização da identidade urbana, da sustentabilidade ambiental e da acessibilidade, aumentando a qualidade de vida de seus usuários. A cidade carece deste tipo de estudo, e suas calçadas que hoje encontram-se em péssimas condições (vide o caso de estudo), não contribuem em nada com a valorização do espaço urbano onde elas se encontram.

\section{Fundamentação teórica}

Durante o século XIX, mais precisamente na segunda metade, grandes cidades europeias, como Londres (1848) Paris (1853), Barcelona (1859), Viena (1857) e Lisboa (1865) começam a passar por transformações urbanas de grande impacto. O urbanismo, naquele momento, assume um importante papel para resolver os problemas criados nas cidades, pela industrialização e pelo forte crescimento demográfico.

As avenidas, as ruas, osboulevares e as calçadas, aparecem, naquele momento, como elementos relevantes dessas transformações, uma vez que além do fator estético, passam também a corresponder o ideal de viver da elite que surge com a nova sociedade, constituindo assim, em elementos importantes da nova infraestrutura e do embelezamento, utilizados para o desenvolvimento urbano e social das cidades.

A regulação do espaço e do tecido urbano é, para muitos autores, quando o assunto é cidade e seu triplo entendimento: urbs, polis e civitas, considerada como questão de ordem social (Cavaco, 2017).

\footnotetext{
"À cidade não é construída para uma pessoa, mas para um grande número de delas, todas com grande diversidade de formação, temperamento, ocupação e classe social. (LYNCH, 2006, p. 123)
} 


\title{
XII SÃOPAULO15 $17 \cdot$ LISBOA $25 \sim 26$ JUN 2020
}

No Brasil, inclusive em Campos dos Goytacazes, essa visão urbana acontece um pouco diferente, as ruas, ou o que poderíamos chamar de ruas, começam a ter atenção e ser realmente pavimentadas e regulamentadas, depois da chegada da Família Real (1808), pois até então, as ruas eram grandes atoleiros e as calçadas (passeios) não existiam(Sousa, 1985), e quando existiam em nada se pareciam com o que vemos atualmente.

Hoje, dentre os principais desafios da Política Nacional de Mobilidade Urbana no Brasil, está o de garantir a eficiência, eficácia e racionalização no deslocamento dos pedestres, promovendo sustentabilidade, acessibilidade, autonomia e atendendo, ao mesmo tempo, aos desejos da população. Nesse sentido, as calçadas são de grande importância para a estrutura urbana das cidades.

De acordo com o CTB, Código de Trânsito Brasileiro, [...] Calçada é parte da via, normalmente segregada e em nível diferente, não destinada à circulação de veículos, reservada ao trânsito de pedestres e, quando possível, à implantação de mobiliário urbano, sinalização, vegetação e outros fins. (CTB, 1997).

Destacamos a importância da caminhabilidade para as cidades e para as pessoas, principalmente no desenvolvimento de uma cultura de pedestres nas ruas e no fortalecimento de oportunidades de encontros casuais se transformarem em forte relações sociais e culturais, e isso é de grande relevância na identidade do lugar e no sentimento de pertencimento (Speck, 2016).

\begin{abstract}
"Apesar de nunca ter sido declarada uma guerra, muitas cidades americanas parecem ter sido feitas e refeitas com a incumbência de derrotar os pedestres. Vias alargadas, calçadas diminuídas, árvores suprimidas, guias rebaixadas para dar acesso a lanchonetes drive-thru e imensas áreas de estacionamento de quarenta mil metros quadrados reduziram muitas das nossas paisagens urbanas a zonas de automóveis, nas quais a vida dos pedestres é apenas uma possibilidade teórica". (SPECK, 2016, p. 25).
\end{abstract}

Assim, considerando a calçada como uma via de passagem, exclusivamente de pedestres, é muito importante que seja agregadora e conectora de emoções e valores que atravessam os tempos pelo fato de desenvolver atividades diversas como caminhar, pedalar, brincar ou outras atividades de natureza formal ou informal. (Lynch,2006; Oliveira,2008; Gehl,2015)

\footnotetext{
"Ruas e calçadas são os órgãos vitais de uma cidade, pois são nelas que acontece a integração e convivência de uma sociedade, sendo que os principais protagonistas do uso e ocupaçãodas ruas e calçadas são as pessoas e transeuntes". (JACOBS, 2014, p. 29).
}

Caminhar, pelas calçadas que hoje temos, deixou de ser um hábito confortável, tranquilo, saudável e principalmente seguro (Speck, 2016; Gehl, 2015). Pedestres, ambulantes, bicicletas, mobiliário urbano aleatoriamente colocado, disputam e dividem as calçadas tornando a vida nas calçadas algo desestimulante e desinteressante.

Sabedores disso, é urgente e necessário se promover uma cidade mais humana, inclusiva, sustentável e resiliente, produzindo e transformando rapidamente o espaço urbano construído, mais precisamente as calçadas, que aqui denominamos de (Des)Calçadas, abordando nessa definição a desconexão existente 


\title{
XII SÃOPAULO15 $17 \cdot$ LISBOA $25 \sim 26$ JUN 2020
}

com as pessoas, as desconformidades das pavimentações, o desconforto de caminhar e a desqualificação das áreas públicas, em um espaço acessível, agradável e com valorização de lugar, o chão projetado, reforçando no uso da palavra chão a ideia de pertencimento e identidade do lugar (Lerner,2005; Oliveira,2008; Gehl,2015; Teles,2013).

\begin{abstract}
"As cidades resultam da ação do homem que cria, ao longo dos tempos, uma relação com os lugares e uma permanente transformação adaptando-se aos condicionalismos e às exigências de cada época. Todas elas necessitam de readaptar as suas estruturas e infraestruturas, as suas formas e usos, às exigências da sociedade". (DUARTE, LOURO, OLIVEIRA, \& GAMITO, 2017, p. 106)
\end{abstract}

As transformações e os projetos de requalificação no espaço urbano, especialmente nas calçadas, possuem papel importante na construção de um sistema de relações entre estes espaços de deslocamentos e as pessoas. Esta relação constitui importante laço que sustenta a requalificação desses espaços públicos e mudança transformadora da paisagem urbana.

\begin{abstract}
"Mais do que qualquer outro elemento da paisagem urbana, o pavimento, assume-se como capaz de se estender e contaminar muito para lá dos seus lugares de origem, acompanhando quem os pisa, no singelo momentode fazer cidade" (OLIVEIRA, 2008).
\end{abstract}

\section{Cenário e Transformação Urbana}

Para melhor compreensão do nosso objeto de estudo, é necessário visualizar o quadro de crescimento urbano que se desenrola no município de Campos dos Goytacazes, principalmente a partir do século XIX.

Até o final do século XVIII a Vila de São Salvador de Campos dos Goytacazes era um pequeno núcleo populacional, sem nenhum conforto, às margens do rio Paraíba do Sul, onde se destacavam alguns trapiches, umas poucas ruas sem calçamento, transformadas em atoleiro com qualquer chuva e um casario tipicamente colonial, igual a muitas outras cidades brasileiras da época, herdeiras das tradições portuguesas. A grande maioria das casas, eram feitas de adobe com cobertura de telhacanal, construídas sob o alinhamento das ruas (casas de face de rua), uma ao lado da outra, com estreitas fachadas compensadas por uma profundidade considerável (grifo nosso)(Sousa, 1985).

No ano de 1835, a Vila de São Salvador é elevada à categoria de cidade, com o nome de Campos dos Goytacazes.

\section{"A pequena vila, pouco tinha progredido desde da sua criação em 1677, contava apenas com uma praça, a Praça Principal ou da Constituição e mais 4 largos - Rocio, Rosário, Pelourinho (ou do Capim) e das Verduras, tinha aproximadamente umas 18 ruas, estreitas e tortas, sem calçadas e algumas ainda sem pavimento."(SOUSA, 1985, p. 18).}

Naquele momento, porém, a cidade começa a apresentar sinais de uma economia crescente e acompanhando as pressões capitalistas e políticas, tinha planos de se tornar capital da província do estado e já desenvolvia discurso abolicionista e republicano. O jornal da cidade, O Monitor Campista, se empenha em 


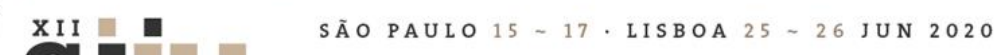

divulgar as mazelas do município e os projetos da Câmara, como forma de sensibilizar a população, diante o quadro crítico da cidade e da necessidade de maiores investimentos por parte dos governos provincial e central(Sousa, 1985)“ [...] é necessário reconsiderar a arquitetura das casas para melhorar a saúde da cidade." (O Monitor Campista, agosto de 1906).

Tal era a cidade incipiente que em vários momentos essa questão foi abordada.

\author{
“... em 1839, em sessão da Câmara, de 19 de Dezembro o vereador José \\ Fernandes Pereira disse que: Estando a Praça de difícil trânsito em tempo \\ chuvoso, propunha o seu calçamento em faixas de 6 palmos, desde a rua \\ Nova do Ouvidor e Travessa do Barroso e desde o Beco da Busca até a rua da \\ Constituição, e em igual largura desde o Porto da Cadeia até a porta principal \\ da Matriz, o que foi aprovado e executado." (SOUSA, 1985, p. 20).
}

Todos esses fatores convergem para transformação e modernização da caótica estrutura colonial, urbana e arquitetônica. A República, as ideias iluministas e positivistas vão inaugurar uma nova Ordem Urbana, com a intenção de igualar o Brasil às grandes nações, ditas civilizadas, recorrendo para isso aos modelos europeus já implantados, em especial o modelo francês. Em Campos dos Goytacazesnão seria diferente, pois vale destacar, que devido a sua importância dentro do cenário político e econômico brasileiro, Campos recebeu o Imperador do Brasil, D. Pedro II, quatro vezes e, em sua última visita em 1883, o imperador inaugurou a luz elétrica na cidade, passando Campos assim, a ser a primeira cidade do Brasil e da América do Sul a possuir esse melhoramento.

Discursos higienistas vão orientar as intervenções urbanas, ocorridas na cidade, durante toda a primeira década do século $X X$, e para vencer o meio insalubre, as enchentes e eliminar a presença dos alagados em pleno centro urbano, novas ruas foram abertas, alargadas e "re"pavimentadas. As ruas agora passam a ter tímidas calçadas de placas de concreto ou pedra e meio fio de pedra, essas mudanças ajudavam na manutenção da limpeza pública e na circulação de pessoas e mercadorias, porém essas pequenas calçadas não apresentavam nenhum aspecto de identidade urbana ou significadomaior, eram sim, uma moldura de proteção ao acesso as edificações e não continham vestígio de embelezamento urbano.

Para uma cidade com pungente economia, passa ser urgente urbanizar e implementar as obras de infraestrutura para atender, não só às exigências e pressões econômicas e políticas, como também ao mesmo tempo, atender as elites que começam a sentir uma crescente necessidade de "modernizar e atualizar a cidade", pondo fim ao atraso colonial e transformando a cidade num símbolo de progresso e de modernização, incorporando no dia-a-dia, práticas consideradas refinadas contribuindo assim para mudanças no comportamento social, que se reveste de sofisticação e requinte.

As modificações ocorridas na esfera social, como moda e costumes, alcançam os espaços construídos, públicos e privados. Varandas e salões coloniais são trocados pela prática da flânerie (termo francês), substituídos pelos passeios nas novas avenidas, praças e jardins, bem à moda parisiense. A elite "passeava" ostentando chapéus, bengalas, sombrinhas, espartilhos e demais modismos europeus vendidos em lojas de luxo e divulgados nas revistas sociais nas publicações da época. 


\section{SÃOPAULO15 $17 \cdot$ LISBOA $25 \sim 26$ JUN 2020}

Seminário Internacional de

Seminario Internacional de Investigação em Urbanismo

É nesse novo cenário urbano, que as calçadas (passeios) passam a ter significado, embelezamento e importância maior, para refletir a nova identidade da sociedade (grifo nosso).

\subsection{Do objeto de estudo}

Situado no município de Campos dos Goytacazes, norte do estado do Rio de Janeiro/Brasil, o bairro nobre da "Pelinca", tem aproximadamente 50 quadras bastante irregulares e muito adensadas. Segundo dados obtidos na Secretaria de Fazenda do município o bairro possui, hoje,o imposto territorial urbano e o metro quadrado construtivodos mais caros da cidade.Mesmo assim, em função da diversidade dos serviços e comércio, atualmente oferecidos, é escolha de moradia altamente procurada.

\section{“...Avenida Pelinca - (Antiga Estrada Covas d'Areia) - No tempo da colônia chamou-se Estrada da Olaria, e houve tempo, pelos anos de 1887-1890, de muito movimento por causa da linha de bonds que ia até o portão da chácara do Chaves, (Pensionato), e ainda mais com o ter lá feito a sua chácara o Vigário Luiz Nobre Pelinca. Era o ponto dos passeios domingueiros aquella «Chácara do Vigário» tão decantada, onde existia uma variedade de pássaros e bichos, constituindo um minúsculo jardim zoológico. Em 24 de Fevereiro de 1888 foi benzida uma bonita capella na chácara com a invocação de Nossa Senhora da Conceição." (SOUSA, 1985, p. 174).}

Tentando respeitar os planos realizados, em especial o Plano Urbanístico de 1944, idealizado pelo escritório do Urbanista Coimbra Bueno juntamente com o conceituado urbanista frances Donat Alfred Agache, a cidade cresce para sudoeste ocupando as áreas vazias da Usina do Queimado, e assim vai somando novos traçados ao tecido urbano inicial. Surge assim inserida no novo tecido urbano e inicialmente com um desenho retilíneo, a avenida Pelinca, sobrepondo-se ao caminho formado pela antiga Estrada das Covas d'Areia. Porém o forte e"tortuoso" traçado da antiga Estrada se mostra mais forte, cria resistência a ação de transformação, não permitindo sua retificação ou seu desaparecimento, impondo seu "velho" caminho ao novo traçadoda avenida construída para atender ao Plano Urbano adotado.

\footnotetext{
"Uma questão que pode ser colocada quando se aborda a relação entre o tempo e a forma da cidade é a da resistência da forma urbana, portanto a resistência de seus elementos urbanos ou dos seus traços à acção transformadora e, porque não, criadora do tempo." (PROENÇA, 2014, p. 33).
}

Apesar das aceleradas transformações na cidade, a avenida Pelinca continua, até os anos 50 do século XX, bem despovoada, um ambiente bastante rural onde só se encontrava alguns poucos solares e grandes chácaras. É somente após a segunda grande guerra, que o bairro, que tem na avenida seu vetor de crescimento, começa a ganhar forma e ser realmente ocupado, pelas famílias de classe alta. A cidade com uma economia em ascensão, acompanhando às exigências do capitalismo, clama pela modernização e transformação da sua caótica estrutura urbana e arquitetônica.

"O bairro a sudoeste da cidade resultou do loteamento de partes das terras pertencentes à fazenda da Usina do Queimado, de propriedade da família Nogueira. Segundo alguns historiadores e moradores antigos do local, o nome 


\section{SÃO PAULO $15 \sim 17 \cdot$ LISBOA $25 \sim 26$ JUN 2020}

Legenda:

I la do Queimado pital Santa Casa de Misericórdia ça da Bandeira

\subsection{A Identidade Urbana do Bairro}

"A cidade se embebe como uma esponja dessa onda que reflui das recordações e se dilata. (....) Mas a cidade não conta o seu passado, ela o contém como as linhas da mão, escrito nos ângulos das ruas, nas grades das janelas, nos corrimões das escadas (...) cada segmento riscado por arranhões, serradelas, entalhes, esfoladuras." (CALVINO, 2002).

Destacamos que na prática, o conceito urbano de planejamento adotado pelos urbanistas, à época da implantação do Plano de Expansão UrbanaCoimbra Bueno e da construção da avenida Pelinca, muito se assemelha a conceitos de planejamentoadotado e implantado em cidades europeias, isto é,a adoção da avenida como um eixo viário,estruturador e indutor do crescimento econômico do novo bairro.

É assim, que o bairro da Pelinca surge, atendendo as exigências de uma nova sociedade. Alicerçado pela avenida, o bairro de vocação residencial confere a elite campista uma nova forma de morar, eesse novo impulso de ocupação vai alavancar a parte sudoeste da cidade em uma área ainda não parcelada.

\section{"....a Av. Pelinca foi construída para o sentido em que as famílias ricas de Campos já se localizavam, ... Gradativamente passaram a atrair novos investimentos do poder público e privado, com a instalação de restaurantes, comércios diversificados e bancos, consolidando-as como novo ponto de centralidade da cidade..." (PEIXOTO FARIA, 2001).}

Com uma identidade urbana exclusivamente residencial, o novo bairro começa a ser organizado e a tomar forma. O parcelamento das grandes chácaras e das terras da usina, resulta em terrenos que mantinham perpendicularidade à frente de rua, apresentavam uma grande diversidade de tamanhos e formas com áreas que variavam de 200 até 400 metros quadrados. As casas e prédios projetados e construídos, que nascem na Pelinca a partir dos anos 50, muito se diferenciavam das casas coloniais ou ecléticas do centro "antigo" dacidade. Apresentam traços modernista que começam a marca presença na arquitetura campista, uma nova tipologia arquitetônica tanto nas construções residenciais como nos novos prédios públicos da cidade.

A identificação da Avenida, como um caminho principal de chegada com características especiais, generalizou-se para designar uma rua diferenciada, mais larga e arborizada (Proença, 2015). Projetada com largura estabelecida de 9 metros de faixa de rolamento e mais 2,5 metros de calçadas em ambos os lados, a avenida Pelinca totalizava 1400 metros de extensão. As medidas extremamente fartasem 1950, são mantidas até os dias atuais,conferindohojeà avenida, visto sua agressiva verticalização, ocupação construtivas muitas vezes desordenadas eainda o aumento excessivo dos veículos em circulação, um aspecto diminuto e desproporcional. 


\section{XII \\ Seminário Internacional de \\ Seminario Internacional de Investigação em Urbanismo Investigación en Urbanismo}

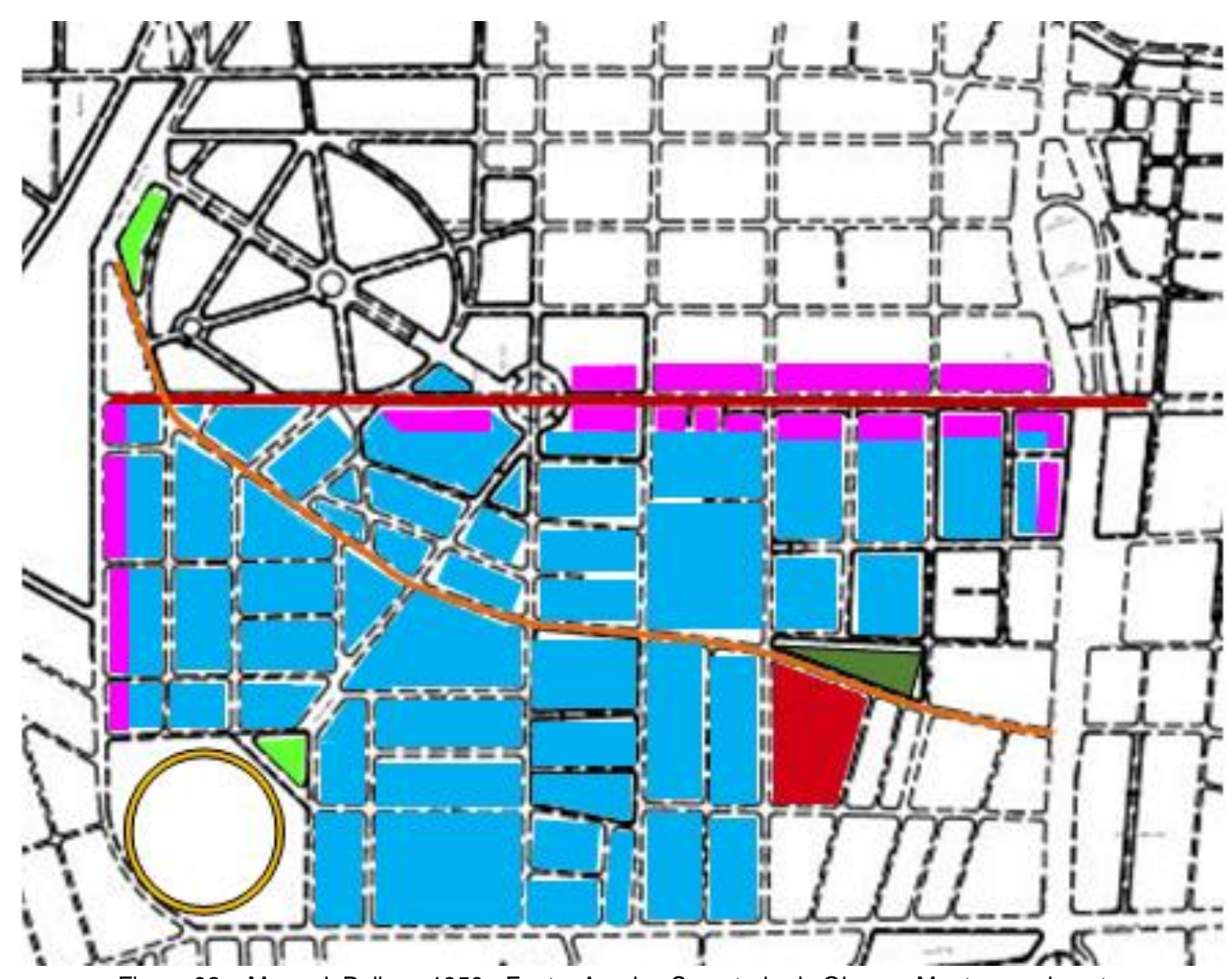

Figura 02 - Mapa daPelinca 1950 - Fonte: Arquivo Secretaria de Obras - Montagem da autora

\section{Legenda:}

Eixo Misto - Av.Formosa

Eixo Principal - Av.Pelinca

Áreas Residenciais

Áreas Verdes

Pç. Da Bandeira

Áreas Comerciais

Hospital Santa Casa

Estádio de Futebol

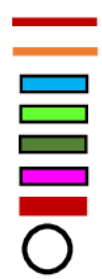




\section{SÃOPAULO15 17 LISBOA $25 \sim 26$ JUN 2020 \\ $10 \begin{array}{ll}\text { Seminário Internacional de } & \text { Seminario Internacional de } \\ \text { Investigação em Urbanismo } & \text { Investigación en Urbanismo }\end{array}$}

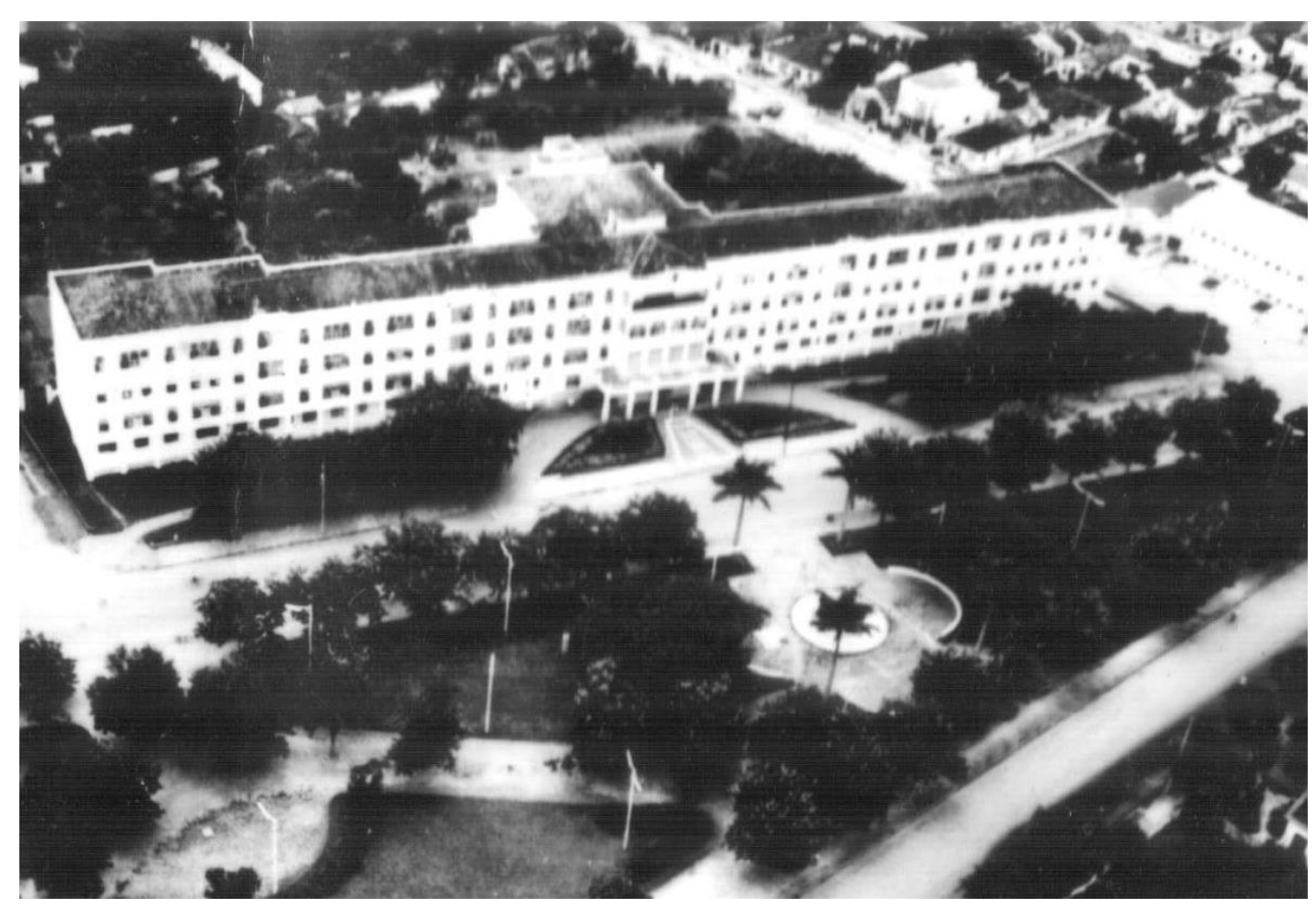

Figura 03 - Foto aérea do bairro - 1960 - Hospital $S^{\text {ta }}$. Casa e a Praça da Bandeira - Fonte: Arquivo Claudio Valadares

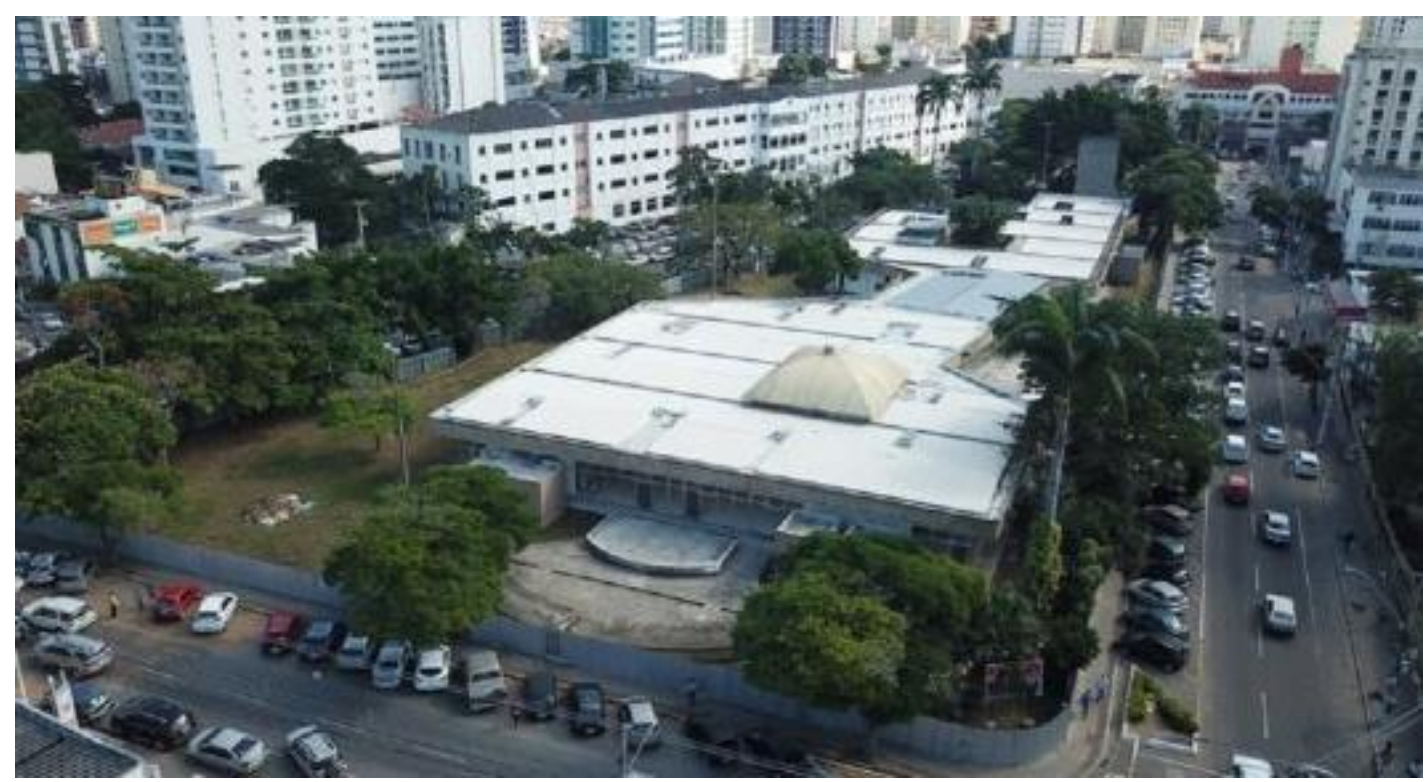

Figura 04 - Foto aérea do bairro - 2020 - Hospital S ${ }^{\text {ta }}$. Casa e a Praça da Bandeira c/ o Palácio da Cultura - Fonte:DaAutora 


\section{SÃO PAULO15 17 LISBOA $25 \sim 26$ JUN 2020}

Hoje, quando observamos a avenida Pelinca, como um caminho indutor, um eixo de grande importânciapara o crescimento da Cidade, encontramos um espaço totalmente oposto ao início da sua ocupação, com uma enorme diversidade de tipologias construtivas e grande desordem urbana.

Percebemos que aquelas ruas e calçadas, aquele chão projetado para a vida residencial, para as brincadeiras das crianças, para as conversas descompromissadasde amigos e vizinhos, o lugar perfeito para saber das novidades, desfrutar a brisa no fim da tarde ou simplesmente, observar o tempo passar, infelizmente já não se visualiza mais.

Os royalties das grandes descobertas de petróleo,aquecendo o orçamento municipal, resultaram em um impressionante crescimento imobiliário, modificando radicalmente a paisagem arquitetônica e urbanística da cidade, principalmente do bairro da Pelinca,onde averticalização se consolida.Desta forma, faz-se necessário estabelecer novos parâmetros de zoneamento construtivos, comercial e residencial,ressaltando-se,que ograndeaumento no volume dos carros possui um importantepapel na transformação do bairro e na imagem da cidade.

\section{As (Des) Calçadas}

O estudo tem como foco, numa primeira análise das (Des) Calçadas, a comparação tipológica dos pavimentos e sua influência (positiva ou negativa), com a mobilidade dos pedestres e num segundo momento o quanto essa tipologia e seu estado de conservação, pode ou não influenciar no sentimento de pertencimento e na identidade urbana da calçada.

Vale destacar, a ausência de políticas públicas voltadas para elaboração de projetos urbanos para construções de calçadas, chão projetado, padronizado, acessível e sustentável, que reflita a identidade do lugar e viabilize os deslocamentos e a mobilidade dos pedestres.

\subsection{Metodologia}

Iniciando a discussão em relação as (Des)Calçadas do bairro e sua falta de identidade com os usuários do lugar, e a possibilidade deconectá-las novamente com os moradores da Pelinca,buscamos viabilizar essa investigação, dividindo o trabalho, inicialmente, em duas grandes etapas. Durante o desenvolvimento da primeira etapa do projeto, foi elaborado um levantamento das tipologias dos pavimentos, em uma área muito movimentadado bairro da Pelinca, o quadrilátero formado pelas ruas: Voluntários da Pátria, Tenente Coronel Cardoso, Barão da Lagoa Dourada e Pelinca, na cidade de Campos dos Goytacazes (Fig. 05).

Durante o levantamento realizado, foi possívelobservar que em diversos pontos desse traçado(Fig. 06), as calçadas existentes se encontram degradadas e em mau estado de conservação e acreditamos que isso se deu, muito, pela falta de ordenamento desses espaços públicospor parte do Poder Público, ao longo do processo de crescimento e desenvolvimento da cidade, que transferiu e imputou ao cidadão a responsabilidade planejar e cuidar das calçadas,fronteiras ao seus lotes,como também muitas vezes pela permissividadee irresponsabilidadeem relação ao uso irregular dos espaços públicos, em especial as calçadas, que aqui denominamos (Des)Calçadas.

Em conjunto com o levantamento de identificação das tipologias de pavimento, aplicou-se também um pequeno questionário, tendo como público alvo os usuários e moradores do bairro, buscando encontrar pontos de conexão e afetividade dessas pessoas com o espaço urbano existente. Para tanto utilizou-se 


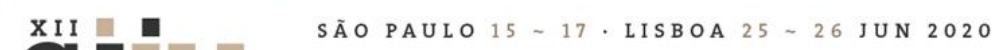

Seminário Internacional de

Seminario Internacional de Investigação em Urbanismo Investigación en Urbanismo

ferramenta digital para dispositivos móveis objetivando maior rapidez na elaboração de gráficos estatísticos e retorno das respostas. Do total das respostas $52 \%$ responderam estar insatisfeitos com as calçadas do bairro e somente $6 \%$ acham os pavimentos bonitos com identidade e unidade visual(Fig. 07).

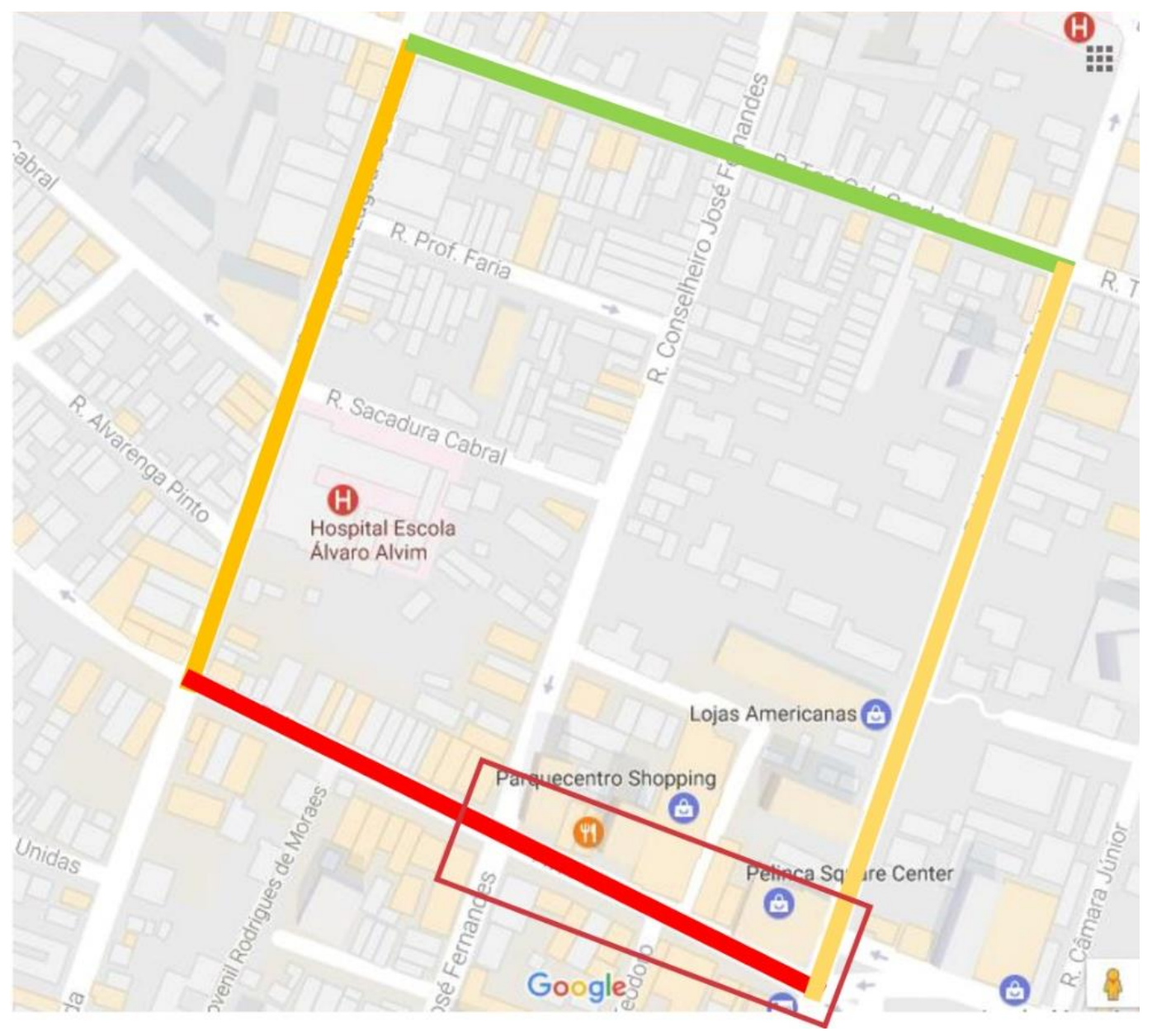

Fig. 05 - Quadrilátero observado e 1ํtecho de calçadas - Fonte: Da autora 


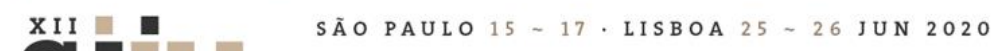

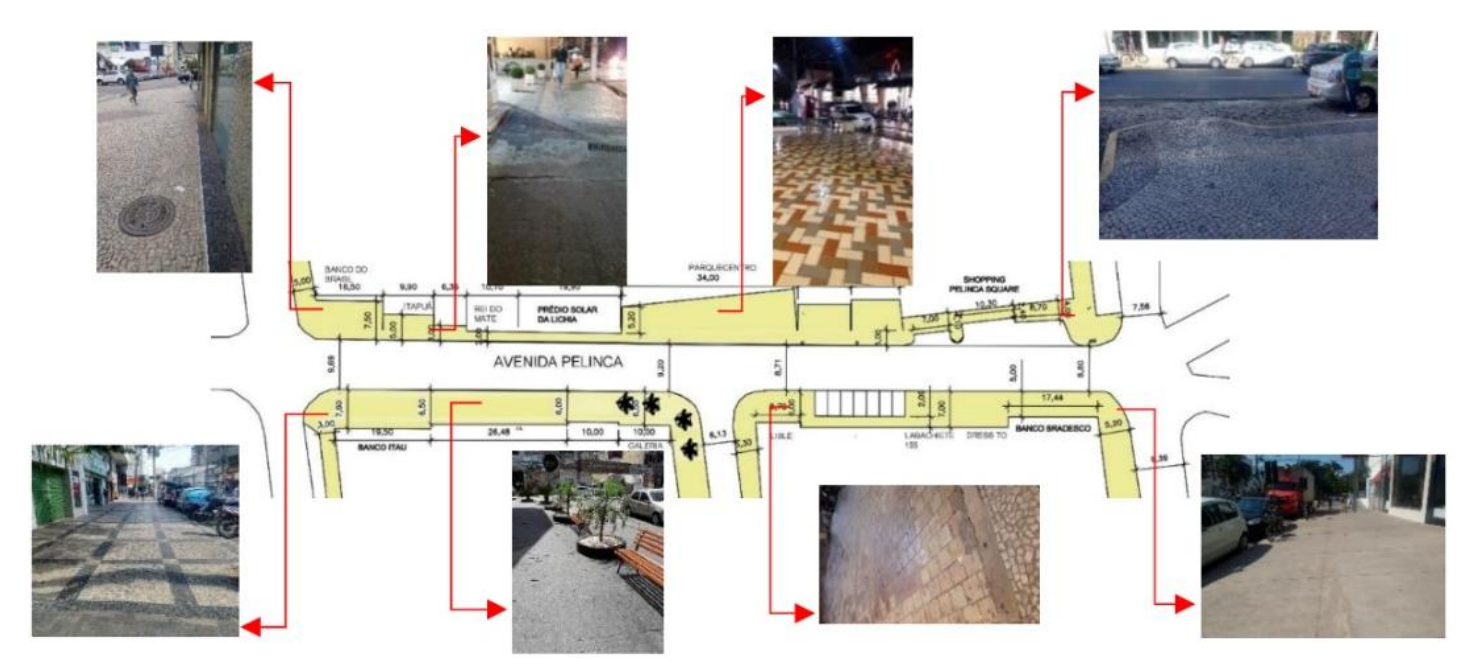

1- CALÇADA À PORTUGUESA

2- CALÇADA DE BLOCOS 3- CALÇADA DE CERÂMICA

5- CALÇADA CIMENTADA

Fig. 06 - Exemplos de pavimentos do 1ำTrecho - Fonte: Da autora

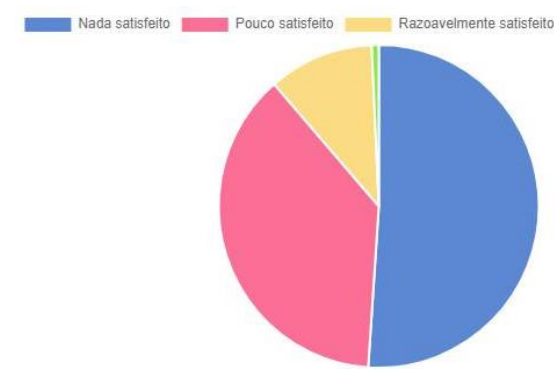

Fig. 07- Resultados parcial da pesquisa - Fonte: Kobo Toolbox

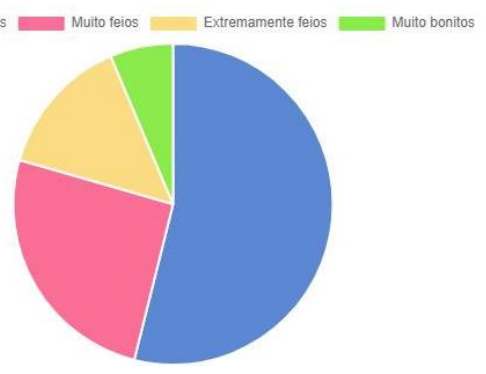

\section{Considerações Finais}

O estudo espera identificar e selecionar, dentro das tipologias encontradas (Fig. 06), aquelas que melhor se ajustem aos parâmetros da requalificação e sustentabilidade dos espaços públicos urbanos, transformando e potencializando a mobilidade dos espaços da cidade, garantindo a acessibilidade com autonomia e segurança para todos os usuários das calçadas, principalmente daqueles com mobilidade reduzida. Independentemente do resultado encontrado, o processo de requalificação e reordenamento das (Des)calçadas, exige a ação de todos os setores da cidade, principalmente do Poder Público, pois a falta de planejamento, gestão e fiscalização em muito contribui para a ruptura das pessoas com os espaços públicos da cidade.

O sucesso da transformação e da requalificação dos pavimentos, do fortalecimento da paisagem e da imagem urbana, certamente depende do encontro ou reencontro das pessoas com sua identidade urbana e coma capacidade delas se reconectarem com o chão projetado, as calçadas, valorizando o sentido de pertencimento do lugar. 


\section{SÃO PAULO15 17 LISBOA $25 \sim 26$ JUN 2020}

\section{Bibliografia}

\section{1 - Referências Bibliográficas}

CALVINO, I. (2002). As Cidades Invisíveis (2ª̂a - 14ª reimpressão ed.). (D. Mainardi, Trad.) Companhia dasLetras.

CAVACO, C. (2017). Urbanismo como política pública que mudanças de azimute? . Lisboa.

FREITAS, F. (2008). Usoe ocupação do solo no bairro da Pelinca: um reflexo na mobilidadeurbana do local.

Campos dos Goytacazes, Brasil.

GEHL, J. (2015). Cidades para PessoaS. São Paulo, Brasil: Ed.São Paulo: Perspectiva.

JACOBS, J. (2014). Morte e Vida de Grandes Cidades. Ed. WMF Martins Fontes.

LERNER, J. (2005). Acumpultura Urbana.

LYNCH, K. (2006). A Imagem da Cidade. São Paulo: Editora Martins Fontes.

MORAIS, J. S., e ROSETA, F. (2017). Avenida da Liberdade: Arquitectura e Cidade (1 ${ }^{\text {a }}$ ed. ed., Vol. 1). Lisboa,

Portugal: Caleidoscópio - Edição e Artes Gráficas, S.A.

NORA, P. (1984). Les Lieux de mémoire - vol. 1 - La République.Paris, França: Gallimard.

OLIVEIRA, F. (2008). O Chão da Cidade. O Plano Esquecido. Arquitetura do Chão e a formação de uma impressão digital urbana. $O$ caso de lisboa. Tese de Doutoramento, 1, 1. Lisboa, Portugal.

OLIVEIRA, F. (2017). Texturas, Pavimentos e Chão. In R. Costa (Ed.), AutentiCIDADE (1 ${ }^{a}$ ed., Vol. 1, 105133) Lisboa, Portugal: Chiado Editora.

PEIXOTO FARIA, T. d. (2001). Projeto de Modernização da Cidade de Campos dos Goytacazes Anos 1870/80.

Anais do IX Encontro da Anpur, 2. Rio de Janeiro, Brasil.

PROENÇA, S. B. (2014). A Resistência da forma urbana. A persistência dos traços na forma da cidade. In C. e. DIAS COELHO, Cadernos de Morfologia Urbana - estudos da cidade portuguesa. O Tempo e a Forma. $\left(1^{\underline{a}}\right.$ ed. ed., Vol. 2ovol., p. 207). Lisboa, Portugal: Argumentum.

SOUSA, H. (1985). Cyclo Áureo. História do Primeiro Centenário de Campos 1835 - 1935 (2ª edição ed.). (D. A. Gráficas, Ed.) RJ, Brasil: Damadá Artes Gráficas.

SPECK, J. (2016). Cidade Caminhável. São Paulo: Perspectiva.

TELES, P. (2013). Cidades de Desejo entre Desenhos de Cidade. Lisboa: Ed. Instituto da Cidades e Vilas com

Mobilidade.

\section{2 - Leis ou Decretos:}

CTB. (1997). Código de Trânsito Brasileiro. Brasil. 